\title{
La configuración de los bienes públicos regionales: un acercamiento desde la perspectiva de la integración centroamericana
}

\author{
Ondina Lourdes Mazier Chávez \\ Universidad Centroamericana, Nicaragua \\ ondina.mazier3@gmail.com
}

\section{Resumen}

La presente investigación expone el estudio de los bienes públicos regionales a través de un análisis desde la postura política de la integración regional. Se orienta a través del Derecho Comunitario que abarca un carácter vinculante en la toma de decisiones del proceso de integración. Se identifica la singularidad de la configuración y creación epistemológica de los bienes públicos regionales generados desde el Sistema de la Integración Centroamericana, como consecuencia de la ausencia de una definición propia de la que adolece el SICA, por lo que se ofrece una serie de características y se construye una enunciación conceptual retomando aspectos fundamentales de los instrumentos originarios y de fuentes doctrinales multidimensionales.

\section{Palabras clave}

Bienes Públicos Regionales / Integración Regional / Derecho Comunitario / Institucionalidad

This research exposes the study of regional public goods through an analysis from the political position of regional integration. It is guided through Community Law which includes a binding nature in the decision making process of integration. This investigation identifies the singularity of the configuration and epistemological creation of regional public goods generated by the Central American Integration System, As a consequence of the absence of a own definition of the SICA. So it offers a series of characteristics and builds a conceptual statement, retaking fundamental aspects of the original instruments and multidimensional doctrinal sources.

Regional Public Goods / Central America Integration / Community Law / Institutionality

\footnotetext{
${ }^{6}$ Investigación realizada en el marco de la Maestría en Integración Centroamericana y Desarrollo, programa conjunto de la Universidad Rafael Landívar de Guatemala, la Universidad Centroamericana "José Simeón Cañas" de El Salvador y la Universidad Centroamericana de Nicaragua.
} 


\section{Tabla de contenido}

Introducción. I. Principales enfoques teóricos de los bienes públicos. I. I. Enfoque jurídico de los bienes públicos. I.2. Enfoque económico de los bienes públicos. I.3. Enfoque desde la cooperación internacional y el desarrollo. 2. Marcó teórico y epistemología de los bienes públicos regionales. 2.I. Bienes públicos regionales. 2.2. Características epistemológicas de los bienes públicos. 3. Los bienes públicos regionales y la integración centroamericana. 3.l. El Derecho Comunitario Centroamericano y los bienes públicos regionales. 3.2. Características de los bienes públicos regionales provistos por el SICA. 3.3. Una aproximación del concepto de los bienes públicos regionales desde la SG-SICA. 3.4. Una aproximación del concepto de los bienes públicos regionales desde la SG-SICA. Conclusiones. Lista de referencias.

\section{Introducción}

La presente investigación pretende considerar y analizar la configuración y creación de los bienes públicos regionales del Sistema de la Integración Centroamericana desde su relanzamiento en el año 2010 , como resultado de las acciones conjuntas y de cooperación entre las instituciones regionales y los Estados centroamericanos. Además, se evidencia que la provisión de los mismos constituye un beneficio tangible del proceso centroamericano. Esta investigación constituye un aporte significativo debido a que desde la constitución del SICA con el Protocolo de Tegucigalpa no se ha desarrollado una identificación de la naturaleza jurídica - política de los bienes públicos regionales y se da respuesta a la siguiente pregunta ¿Qué son los bienes públicos Regionales en Centroamérica? Y ¿Cuál es su tratamiento dentro del Sistema de Integración Centroamericana?

En el primer acápite se desarrollan antecedentes históricos de las principales teorías de los bienes públicos desde el enfoque jurídico del Derecho Romano y Derecho Administrativo, asimismo se desarrolla el enfoque económico de los bienes públicos a partir de las teorías clásicas, y las posturas de la cooperación internacional y su vinculación con el desarrollo humano.

A continuación, el segundo apartado de esta investigación expone el marco teórico y la epistemología de los bienes públicos; se explica la naturaleza de los mismos y las principales teorías conceptuales para su correcta configuración, vinculando la permisividad epistemológica de estas teorías con el Desarrollo Humano.

Y, por último, el tercer apartado realiza un acercamiento del abordaje y tratamiento de los bienes públicos regionales dentro del proceso de la Integración Centroamericana y su marco institucional. Se ofrece una aproximación de concepto, desarrollado a partir de la pertinencia de las teorías abordadas en el apartado dos, se recogen cuatro entrevistas cualitativas con una técnica de muestreo teórico, con preguntas de naturaleza indagatoria dirigida a expertos vinculados al SICA; además se exponen características identificadas desde el carácter sui generis de estos bienes generados desde el sistema jurídico centroamericano.

La investigación realizada es de carácter cualitativa; se realizó análisis y sistematización de documentación teórica adecuándola al contexto y realidad centroamericana, logrando identificar la configuración de los bienes públicos regionales como resultado de las acciones conjuntas y de cooperación entre las instituciones regionales y los Estados centroamericanos que permitirá aumentar la creación de estos bienes, y facilitar los procesos de construcción técnica y su medición de impactos que estos puedan generar. 


\section{Principales enfoques teóricos de los bienes públicos}

\section{I. Enfoque Jurídico de los bienes públicos}

Los antecedentes históricos en materia jurídica acerca de la construcción y configuración de bienes públicos se plantean desde dos perspectivas: la primera del Derecho Romano y la segunda del Derecho Administrativo, ambas ramas jurídicas denotan aspectos fundamentales de la epistemología de los bienes destinados a fines públicos.

Desde la exégesis jurídica, se considera bienes a aquellas unidades que abarcan el uso y disfrute de la utilidad de un bien y al agente que lo provisiona. Las antiguas concepciones Romanistas al referirse a la titularidad común planteaban, que estos derechos al recaer sobre cosas públicas pertenecían a todos los seres humanos de las civitas ${ }^{7}$, por lo tanto, no tenían titularidad particular y no entraban dentro del tráfico jurídico ya que no eran derechos reales, es decir, un derecho subjetivo cuyo aprovechamiento podía ser total o parcial y que era exigible erga omnes ${ }^{8}$.

Los aportes romanistas, permiten comprender cómo las primeras organizaciones de repúblicas y de sociedades organizadas gozaban de derechos sobre cosas públicas dentro de las comunidades habitadas; esta condición permitía mejorar ambientes de vida o disfrutar de un derecho que sin la intervención de sus gobiernos era imposible usufructuarlo, sin embargo, en nuestro sistema de derecho actual, los bienes con titularidad de públicos son aquellos que pertenecen y son provistos por las administraciones públicas o las instituciones homólogas a los Estados que gozan de supranacionalidad, por ejemplo los procesos de integración.

El tratamiento jurídico de las cosas públicas se ha configurado desde el Sistema Jurídico Romano con las Partidas ${ }^{9}$, donde por primera vez se establece la diferencia del derecho sobre una cosa pública en relación al derecho sobre una cosa privada. Estos derechos sobre cosas públicas eran denominados como La Res, que se designaba a "todo objeto del mundo exterior que puede producir alguna utilidad al hombre" (Morineau., y Iglesias, 1998; p. II2). Cabe añadir a esta definición, que jurídicamente se denomina como cosa, al objeto de las relaciones jurídicas que pueden ser corpóreas o incorpóreas, materiales e inmateriales.

Hacia el año 55 antes de Cristo, Cicerón (I, 39) en su libro la RE PÚBLICA (la cosa pública) define la denominación pública e inherente de ciertos bienes dentro de Roma, éste los clasifica de la siguiente manera: "la res publica es la res del populus Romano", esta locución latina hace una distinción entre los bienes patrimoniales y los bienes de uso público que las personas en las civitas podían consumir y aprehender, su semántica era referida a la gestión pública de la República al otorgar al pueblo derechos comunes (Betancourt, 2007). Para Cicerón, el pueblo, a quien estaban dirigidas estas cosas públicas se constituía como una sociedad organizada que se sirve de un derecho común provisto por el gobierno.

\footnotetext{
${ }^{7}$ Civitas es una locución latina perteneciente al Derecho Romano que significa "comunidad ciudadana", "ciudadanía", "ciudad".

${ }^{8}$ Locución latina que significa que jurídicamente un derecho que recae sobre un bien mueble, inmueble, material o inmaterial puede ser exigido por su titular frente a terceros y que es susceptible de entrar al tráfico jurídico por quien ostente su derecho.

${ }^{9}$ Cuerpo normativo o "códice, escrito durante 1252-1284, que incorpora 7 estamentos legales del reino de Castilla con el propósito de armonizar de acuerdo al derecho común basado en el derecho romano de Justiniano.
} 
En el Derecho Romano se establecieron estatutos jurídicos para los bienes con categoría de pública en sub categorías, dictaminadas por juristas a partir de la influencia Justiniana. Estas sub categorías de cosas públicas se encontraban establecidas en instituciones como Res Publicae in uso público, que a la vez se desmembraba en sub clasificaciones como las res Universitates, las Res Communes ómnium, y además dentro de este sistema existían los bienes Res in patrimonio populi que se explicaran a continuación.

La primera institución de la Res Universitates estaba referida a aquellos bienes indivisibles del pueblo romano que, por su propia naturaleza, no eran objeto de apropiación ni de comercialización, sino que podían ser servidos y disfrutados por todas las personas sin exclusión. Estos bienes pertenecían a la organización de la República, como ejemplo estaban: los ríos, las plazas públicas, los faroles de luz, los puentes y todos aquellos centros culturales o de reunión como los teatros (Vallejos, 2005).

De la misma forma, la Res Communes ómnium eran todos aquellos bienes naturales incapaces de ser aprehensibles, derivados del derecho natural que se les daba la categoría de bienes intangibles e inmuebles; esta concepción antigua fue desarrollada por primera vez por Marciano durante su reinado 450-457 antes de Cristo (Betancourt, 2007). En el Derecho Romano clásico se categorizaba a este tipo de bienes -a diferencia de otros- porque el ser humano no posee una intervención directa para crearlos, ni para sostener su durabilidad en el tiempo, ejemplo de ello son las costas, los mares y el aire.

Como última institución se encuentra las Res in Patrimonio Populi que a pesar de ser bienes del populus romanos, eran bienes susceptibles de entrar al tráfico jurídico y ser adquiridos por los particulares cuando se realizaban negociaciones con el Estado. Estos bienes podían causar beneficios pecuniarios, además estaban protegidos por un régimen similar al del patrimonio privado. Cabe mencionar, que las características inalienables e inherentes de los bienes categorizados como públicos en el Derecho Romano estaban referidos a la gestión pública, donde se ofrecía el disfrute de derechos comunes que podían ser gustados por todos por medio de un gobierno público.

Por otra parte, el derecho administrativo aborda que un bien puede ser considerado bajo dominio público dependiendo de la titularidad que puede ostentar, esto excluye consecuentemente el régimen privativo susceptible al tráfico jurídico. El Estado es el garante de proveer derechos y servicios que recaen sobre aquellos bienes materiales $o$ inmateriales que puedan ser consumidos por los habitantes de una determinada región geográfica.

La tradición jurídica en Centroamérica retoma como doctrina para la creación de postulados en materia de derecho administrativo al Derecho Español, por tanto, de acuerdo a (López, 20I2) el régimen especial de los bienes y derechos de dominio público está integrado por un sistema jurídico protector, regido por la incomerciabilidad que simboliza la inalienabilidad, imprescriptibilidad e inembargabilidad de estos bienes, esta última se encuentra en nuevos debates contemporáneos donde se pone en discusión, si los bienes públicos producidos por el Estado son susceptibles de embargabilidad, no obstante, dicha discusión no entrará en debate en esta investigación.

En ciertos ordenamientos jurídicos europeos de donde también Centroamérica recibe influencia, los bienes de carácter público no poseen un rango constitucional ni jurídico correspondiente al dominio público, tal es el caso de Italia que la regulación de los bienes de patrimonio disponible corresponde por entero al Derecho Privado, de igual forma sucede en el ordenamiento jurídico alemán (Sánchez, 1997).

Estos dos sistemas reconocen a los bienes públicos como bienes patrimoniales, es decir, aunque pertenecen a las administraciones públicas de los Estados, no están servidos a usos generales, a no ser, que estos Estados otorguen algún régimen de especial regulación. Tales bagajes jurídicos 
diferenciales corresponden más a las condiciones generacionales y económicas de los Estados que los coartan de ser proveedores de los mismos.

Es importante señalar que los bienes públicos dentro del régimen jurídico deben poseer por parte de la Ley una categorización, donde primero se clasifique qué tipo de bien ha producido el Estado, y una vez identificado se debe elevar al status jurídico de bien público. La determinación permite qué tipo de protección jurídica va a resguardarlos, ya sea en un mayor o menor grado hasta poder satisfacer necesidades fundamentales o accesorias por las que fueron provistas.

En el derecho administrativo para que un bien sea considerado público dependerá principalmente de la titularidad que estos puedan poseer, es decir, un bien material, inmaterial, tangible o intangible, perecedero o no perecedero teniendo una titularidad privada puede ingresar a las arras del Estado y constituirse como un bien público porque su funcionalidad estará al servicio de un objetivo popular, incluso hay bienes públicos que se originan por competencias asignadas a las instituciones.

En otras palabras, estos bienes para existir tuvieron una intervención institucional -por ejemplo, la infraestructura vial en una zona rural- por el Estado, generando un impacto positivo y paleando una necesidad de desarrollo ya sea local que puede trasladarse a un ámbito regional coadyuvando las conexiones viales intrafronterizas. De la misma forma se encuentran los bienes generados por un proyecto regional como la electrificación de interconexión eléctrica, donde los Estados se coordinan a través de sus interdependencias y niveles de integración, aquí podemos observar un elemento que se adhiere a la provisión del bien, el carácter estatal y un carácter multilateral.

Dentro de las características de los bienes públicos en el derecho administrativo se identifica primero, que la titularidad de estos bienes no se encuentre en posesión de un particular sino que a través del Estado o una institución regional o local sea quien provea y proteja la integralidad del bien, como segunda característica está la utilidad del bien que debe ser dirigido a un destinatario colectivo, ya sea para una función pública o para consumo de los administrados de un territorio, la tercera característica es la inembargabilidad del bien cuando esté sujeto a un servicio público o de utilización pública.

Una cuarta característica es el beneficio y el impacto positivo sobre quienes está ofrecido su consumo, esto permite reducir las brechas de rendimiento y potencia el incremento productivo o de desarrollo de una región o localidad. Esto se puede evidenciar en mejoras de servicios y atención a ciudadanos, por ejemplo, el desarrollo del comercio intrarregional en Centroamérica, este bien público accede a mediano plazo reducir el hambre y abonar a la seguridad alimentaria, permitiendo medir impactos de forma cuantitativa a corto plazo.

\section{I.2. Enfoque económico de los bienes públicos}

En esta dimensión de análisis, (Samuelson, 1954), (Stiglitz, 2003) y (Cantarero, s, f) desarrollan el tratamiento de los bienes públicos desde el enfoque económico por medio de la Teoría Pura del Gasto Público y expresan que los bienes públicos se clasifican entre lo puro y lo impuro además, satisfacen necesidades sociales frente a las externalidades del mercado; sin embargo, desde esta perspectiva, la coordinación entre Estado y Mercado para el suministro de bienes públicos debe ser complementaria.

Los bienes públicos en la economía pueden considerarse una externalidad. Esta característica transita manifiestamente la literatura económica sobre las relaciones internacionales. La teoría económica neoclásica establece que un mercado competitivo encuentra el equilibrio donde el beneficio marginal privado iguala el beneficio público. Para que estos bienes sean considerados como públicos, las 
externalidades positivas o negativas deben afectar a una cantidad elevada de personas y el bien no debe presentar un carácter de exclusividad ni rivalidad (Francés, 20I2).

Para (Schiff y Winters, 1997) quienes desarrollan las externalidades de los bienes públicos desde los Acuerdos Regionales de Integración (ARI), exponen que los bienes públicos dentro de los esquemas de integración obedecen a tres tipos de externalidades. El primer tipo de externalidad se desarrolla desde el enfoque de la teoría vineriana ${ }^{10}$, un beneficio de second best, se refiere a la seguridad que proporcionan los procesos de integración regional, y su capacidad de potencializar externalidades positivas que permitan las relaciones exteriores y comerciales entre los Estados, frente a desviaciones del comercio que pueden ocasionar menoscabos sociales hasta convertirse en una deuda pública.

El segundo tipo de externalidad es el aumento de la seguridad de los países suscritores. De acuerdo a (Francés, 20I2):

Esto puede obedecer a que de ese modo se facilita el desarrollo económico de un país cuya conflictividad se achaca a cuestiones en buena parte económicas; o a que la propia integración puede suponer, hasta cierto punto, una respuesta ante un tercer país que amenaza al conjunto de Estados que se integran (p. 45).

El tercer tipo de externalidad positiva desde la economía es aquella que puede generar beneficios culturales ya que las sesiones de soberanía generadas por los procesos de integración o Acuerdos Regionales de Integración, inducen a los países miembros a inclinarse en asociaciones con otros países que posean afinidades culturales y compartan historias comunes que abonarían a la conservación de su idiosincrasia directa.

Para (Hanss-Hermann, 1993) ciertos bienes o servicios no están limitados a ser consumidos o hacer uso de los mismos únicamente por las personas que han contribuido con su financiación, sino que están ofrecidos generalmente a ser disfrutados, y aduce "que esta característica especial de los bienes públicos es la que determina que los mercados no los produzcan, o por lo menos, no en la cantidad o la calidad suficiente, por tanto, se necesita la acción compensadora del Estado" (p. 2).

\section{I.3. Enfoque desde la cooperación internacional y el desarrollo}

El nuevo contexto mundial de la cooperación internacional está en reajuste para la adecuación estructural de su modelo de gobernanza, con el fin de alcanzar niveles de eficacia real en la ayuda al desarrollo. En este sentido, dentro del pre diseño estratégico de la cooperación, los países socios ejercen una serie de negociaciones dinámicas con base primeramente a una demanda que los países del sur o subdesarrollados proponen, fundado en sus políticas nacionales de desarrollo y en la identificación de las necesidades latentes que provocan desigualdades. A la vez los países oferentes, es decir, países con niveles de renta alta o países desarrollados proponen una serie de proyectos fundamentados en componentes consensuados internacionalmente por Declaraciones, Planes de Acción y Foros de Alto Nivel.

La cooperación para el desarrollo propone ampliar las potencialidades humanas con el objetivo de lograr un impacto en el desarrollo de las naciones, de igual forma para la superación de la pobreza, las marcadas desigualdades, el desarrollo humano, entre otras; estas son metas prioritarias para los

\footnotetext{
${ }^{10}$ De acuerdo a Jacobo Viner (1950) con su Tesis de Uniones Aduaneras exponía dos enfoques de análisis de los beneficios económicos que podían producir los acuerdos regionales a partir de la liberalización del comercio y la desviación del comercio.
} 
países donantes y para la comunidad internacional, así como la aplicación compartida de los principios establecidos en la Declaración de Paris, Bussan, Accra y la corresponsabilidad de las acciones y de la eficacia (Álvarez, 20I2).

Al respecto, existen principios prioritarios para la ayuda al desarrollo, que sirven como marco referencial en la dinámica adecuación de la cooperación, a la vez se constituyen como una base normativa no vinculante para los países, ya que la adecuación de cada uno de ellos no es homogénea y cada país receptor posee particularidades que varían dependiendo de la región, factores endógenos, exógenos y realidades características de cada país, por lo cual la aplicación de estos principios en un ámbito regional se debe homogenizar paulatinamente cuando se actúa de forma colectiva.

La Declaración de Paris del año 2005 ha desarrollado tres principios aplicables a la Cooperación, el principio de Apropiación, que establece que los países socios, es decir, los países receptores deberán ejercer una autoridad efectiva sobre sus políticas de desarrollo, estrategias y coordinación de acciones que vayan encaminadas a ejercer un rol de liderazgo de sus programas operativos $y$ prioritarios que les permita manifestar sus capacidades y expandirlas de una forma incluyente donde participe la sociedad civil y la empresa privada.

En cuanto a la Armonización, la Declaración de Paris dispone que los donantes posean acciones armonizadas, transparentes y colectivas que logren alcanzar la unión de procedimientos separados y evitar la fragmentación excesiva de la ayuda a escala global, nacional o sectorial (Declaración de Paris, 2005).

De la misma forma en el principio de Alineación, los donantes basan todo su apoyo en las estrategias, instituciones y procedimientos nacionales de desarrollo de los países socios, por lo tanto, los donantes utilizan los reforzados sistemas nacionales de los países para la "gestión de finanzas pública, contabilidad, auditorías, aprovisionamiento, marcos de resultados y supervisión, diagnósticos y marcos de evaluación del desempeño" (Declaración de Paris, 2005, p. 4).

Los países socios ejercen una serie de negociaciones dinámicas con base primeramente a una demanda que los países del sur o subdesarrollados proponen, establecido en sus políticas nacionales de desarrollo y en la identificación de las necesidades latentes que provocan desigualdades, a la vez los países oferentes de estos bienes, es decir, países con niveles de renta alta o países desarrollados proponen una serie de proyectos basados en componentes consensuados internacionalmente (Álvarez, 2012).

Al respecto, organismos internacionales como la Comisión Económica para América Latina (CEPAL, 2009), identifica posturas acerca de la provisión y oferta de los bienes públicos regionales tomando como instrumentos a la cooperación para el desarrollo. El Banco Interamericano de Desarrollo ha considerado entre sus líneas de acción, una articulación de esfuerzos dentro de los procesos de regionalismo adoptados por América Latina y el Caribe, proponiendo mecanismos de asistencia técnica y de financiamiento (Bocalandro y Villa, 2009), así como propuestas de áreas prioritarias de acuerdo a las Agendas Mundiales de Cooperación (Rozemberg y Rozenwurcel, 2012).

El Banco Interamericano de Desarrollo (BID) ha desarrollado un concepto de bienes públicos regionales como base a la ejecución de un proyecto sobre soluciones innovadoras que darían respuesta a la producción de bienes públicos:

Es un tipo de solución del ámbito transnacional para aquellas fallas de mercado que se han agudizado como resultado de la globalización (Villa, 2007a). Los bienes públicos regionales corrigen problemas que no han encontrado respuesta en acciones individuales de cada país, o que no ofrecen incentivos a un solo Estado 
para que asuma el costo de llevarlas a cabo citado por (Bocalandro y Villa, 2009, p. 3).

De igual forma, el (Banco Interamericano de Desarrollo, 2016) define como bienes públicos regionales todos aquellos "bienes, servicios o recursos que sean producidos y consumidos colectivamente por el sector público y, donde sea apropiado, por el sector privado sin fines de lucro en un mínimo de tres países miembros prestatarios del BID” (p. I). En esta definición el BID introduce a personas naturales o jurídicas como beneficiarios finales de los bienes públicos.

Estas dos últimas aproximaciones conceptuales que realiza el BID desde el enfoque de cooperación internacional contrapone e introduce al debate las teorías económicas y jurídicas que se han planteado desde la introducción de este capítulo, partiendo del supuesto que un bien público tendrá como elementos principales quien los produce y quien los consume, considerando que un bien público es provisto por los Estados, sus Administraciones Públicas, el sector privado y el Derecho Comunitario a través de sus instituciones supranacionales facultadas al respecto.

Los bienes públicos en general se constituyen como medios para potenciar el desarrollo humano de los Estados, entendiendo como desarrollo humano toda su multidimensionalidad y multisectorialidad dentro del desarrollo económico y social. Sin embargo, los problemas estructurales -que frenan el desarrollo económico- de los países miembros del sistema como la violencia, la deficiencia educativa, variabilidades de políticas microeconómicas entre otras, no pueden ser resueltos a través de provisión de bienes públicos regionales.

En Centroamérica, se ha apostado por la integración como un modelo de desarrollo mediante un plan estratégico regional y la creación de marcos jurídicos multidisciplinarios, que permita lograr un modelo donde los Estados partes puedan alcanzar objetivos comunes, bienes regionales por medio de instituciones supranacionales a través del Sistema de Integración Centroamericano.

Los bienes públicos poseen dos variables por las que son constituidos con fines de desarrollo, el primero es que se proveen con fines de integración ejemplo la Unión Aduanera, un Mercado Común o hasta políticas macroeconómicas a nivel regional como eliminación de barreras arancelarias, armonización legislativa en materia económica que facilite el comercio, entre otras; y por otro lado, están aquellos bienes que son creados con fines de cohesión social y desarrollo en capital humano como las políticas públicas en materia educativa, una visa única centroamericana, la compra conjunta de medicamentos, estrategias contra el cambio climático, entre otros.

Todos los esquemas de integración como modelos de desarrollo son propicios a la producción de bienes públicos regionales y a la vez incrementan su demanda de provisión. Por consiguiente, se constituyen como un catalizador de la cooperación para el desarrollo que juega un rol fundamental en la gestión presupuestaria para su provisión.

\section{Marco teórico y epistemología de los bienes públicos regionales}

\section{I. Bienes públicos regionales}

La clasificación de los bienes públicos está supeditada desde un enfoque espacial, es decir, que para que un bien pueda ser Global, Regional, Nacional o Local dependerá del alcance y el impacto que puedan tener estos bienes sobre una determinada geografía, así como de las políticas y sistemas jurídicos. 
Estos bienes serán regionales cuando afectan a dos o más países territorialmente cercanos y, además, sean relativamente homogéneos en características geográficas, sociales, culturales y hasta políticas. El carácter regional puede realizarse por esquemas de procesos de integración, acuerdos binacionales comerciales o políticos, o la construcción de un bien por un Estado que posea el efecto spillover sobre otros Estados.

Para (Morrissey, et al, 2012) "un bien público regional se define porque los beneficios o utilidades que produce se acreditan al público de las naciones con fronteras continuas" (p. 4) [Traducción propia] ante esta definición se destacan dos características importantes, en primer lugar, se refiere a la proximidad territorial de los países para el derrame del bien, para los países en su conjunto y la segunda, el beneficio que debe producir como requisito sine qua non ".

Estos bienes se constituyen con el propósito de corregir los problemas transnacionales que no han encontrado respuesta en acciones individuales de los Estados o que carecen de incentivos para que puedan ser asumidos y llevados a cabo. (Chorro, 2010) De igual forma los bienes públicos desarrollados en un segmento regional tienen el fin de potenciar las coordinaciones de los Estados próximos para garantizar bienestar a sus poblaciones, a las economías y al medio ambiente que es más difícil consumar con esfuerzos individuales.

La integración permite afrontar las externalidades de los mercados, creación de economías a escala, accede la especialización productiva de la región y beneficios comerciales mutuos, presencia internacional y cooperación (Santos, 2006). Todos estos elementos se categorizan como bienes públicos producidos por la inducción positiva de la interrelación que los procesos de integración engendran.

Según (Morrisey et al, 2002) con respecto al nivel de utilidad que pueden alcanzar estos bienes, los mismos tienen la capacidad de reducción de males públicos y de externalidades negativas, o eliminación de todos aquellos elementos que provoquen des utilidades. Un ejemplo común es la reducción de la pobreza que además posee una funcionalidad de servicio público, mermar la creciente degradación del medio ambiente en general, establecer políticas macro y microeconómicas que permitan enfrentar las variabilidades económicas del mercado mundial como políticas cambiarias, entre otros.

Asimismo, la integración política abarca un carácter vinculante en la toma de decisiones de los Estados del proceso integracionista (Malamud, 2010). Los mismos se someten a una dinámica de homogenización de las políticas regionales comunes -que superan el aspecto meramente económicoque dependen de un órgano supranacional a quien se le cede soberanía para que dicte, regule y ejecute con la voluntad política de los países y sus órganos gubernamentales. Estas políticas públicas regionales o tratados internacionales vinculantes pueden llegar a constituirse como bienes públicos o utilidades regionales.

En consecuencia, la integración centroamericana se considera como un bien público regional sujeto a un marco institucional y de políticas públicas que permiten aumentar y generar bienestar a partir de una gobernanza intergubernamental. La institucionalidad de la integración centroamericana es primordial como elemento para lograr la generación de políticas públicas y bienes públicos hacia objetivos de bien común regional plasmados en diferentes instrumentos del sistema integracionista (Chorro, 20I0).

\footnotetext{
"Locución latina con carácter jurídico que significa la condicionalidad de un elemento para la construcción del todo de un elemento, "sin el cual no".
} 


\subsection{Características epistemológicas de los bienes públicos}

De acuerdo a su concepción epistemológica los bienes públicos poseen características esenciales para clasificarlos. El adjetivo público está condicionado a características que se manifiestan en la clasificación espacial o territorial donde derrama sus efectos.

Gracias a (Samuelson, 1954) se desarrollaron dos características principales acerca de los Bienes Públicos relacionadas al consumo del bien: la no exclusión y la no rivalidad, que a continuación se exponen.

No exclusividad: Una vez provisto el estatus de no exclusividad, el beneficio o utilidad que produce el bien, debe estar al alcance de todas las personas independientemente de razones económicas, sociales o culturales, por ello su consumo no será excluible. Esta característica conlleva al concepto de externalidad que consiste en que "las externalidades surgen cuando una persona emprende una acción, pero no sufraga todos sus costos, externalidad negativa o todos los beneficios externalidad positiva de la acción”. Stiglitz, J. (1997). (Como citó Velásquez, 2009, p. 15)

Es decir, los bienes que generen externalidades positivas pueden ser ejecutables directamente ante la producción de la utilidad de este bien por los agentes que pueden consumirlo. Una externalidad positiva es un elemento que tiene valor pero que no conlleva un precio.

No rivalidad: Una vez ofertado y consumido el bien, éste no sufre menoscabo frente a otros consumidores ni reduce la oferta disponible, no genera costo que provoque una preferencia de consumo.

Esta característica se logra "cuando el costo marginal de una unidad adicional de consumo del bien público es igual a cero. $O$, es decir, que cualquiera puede consumir el bien público sin límite, a diferencia del bien público privado, cuyo consumo adicional tienen un costo marginal superior a cero" (Velázquez, 2009: p. 14).

La epistemología de los bienes públicos nos señala que estos deben poseer el carácter de una triple dimensión de desarrollo para su determinación; por tanto, un bien público debe poseer un carácter "interpersonal, internacional e intergeneracional" como lo define (García-Arias, 2004: p. 192) en otras palabras, debe tener la capacidad de no ser excluyente y que su consumo sobrepase una delimitación de beneficiarios. Con respecto al carácter internacional se refiere a que sus efectos no se concentran en único territorio geográfico, sino que sobrepasa las fronteras y, por último, la capacidad de elasticidad intergeneracional.

En esta misma conjunción de ideas, existen otras características accesorias de los bienes públicos que posibilitan su identificación según su provisión.

Universalidad: De acuerdo a las teorías clásicas del neo funcionalismo, los procesos de integración han desarrollado un dinamismo en sus agendas políticas. Esta evolución provoca beneficios tangibles a la población y a su vez, impactan en los procesos de integración para que puedan constituirse como sistemas capaces de reducir asimetrías y de gozar bienes públicos bajo un carácter universal (Dabené, 20I2).

En ese mismo sentido, los bienes públicos pueden constituirse bajo la característica del efecto spillover o efecto dominó, cuando las fallas de los mercados menoscaban el desarrollo en las poblaciones; razones que inducen la intervención del Estado y a su vez, se presenta como una oportunidad para producir bienes públicos. Por tanto, el efecto spillover provoca la universalidad de los mismos, es decir, que pueden constituirse en beneficio para quienes no han pagado por ello. 
A su vez, los bienes públicos pueden clasificarse de acuerdo a la variabilidad frente a los consumidores en:

Bien público puro: Es aquel que posee dentro de su configuración las dos características principales de la doctrina económica de los bienes públicos: la no exclusión y la no rivalidad. Se caracterizan por cumplir totalmente con la característica de no rivalidad.

Bien público impuro: Consisten precisamente en lo contrario de los bienes puros, el consumo de estos bienes tiene una parcialidad de rivalidad, es decir, que tiene una limitación de beneficiarios por lo tanto genera exclusión, en este sentido para (Pérez, Soto y Pellandra, 20I2):

Esta categoría de bienes públicos son sencillamente un caso intermedio entre los denominados bienes públicos puros (los que cumplen totalmente con el principio de no rivalidad) y los bienes privados (aquellos cuyo consumo es totalmente rival). La existencia de bienes públicos impuros pone de manifiesto que: el carácter de público referido a un bien es más una cuestión de grado (relativa) que una propiedad absoluta. (p. 57)

Opcionalidad: Los bienes públicos también tienen característica de ser una opción para su consumo, es decir que un consumidor puede decidir si consumir o usufructuar cierto bien o de lo contrario no hacerlo. Un bien posee un valor de oportunidades que no requiere obligatoriamente ser susceptible de consumo; por lo tanto, subjetivamente tiene el derecho a ser elegido y éste elemento de opcionalidad no menoscaba su naturaleza de carácter público. Sin embargo, esta característica no se puede aplicar en bienes ya creados, solamente a aquellos que no son elementales o indispensables como las emisiones radiofónicas.

\section{Los bienes públicos regionales y la integración centroamericana}

Los procesos de integración regional si bien es cierto nacen con un fin macroeconómico y evolucionan a la creación de instituciones regionales que se encargan de temáticas extra económicas comunes en la región.

La integración regional tiene que ser comprendida desde dos enfoques: el económico y el político. El primero se consolida con la integración económica que tiene como punto de partida la Teoría Clásica del Comercio Internacional, como lo menciona Cohen Orantes citado por (Santos, 2006): "proceso mediante el cual dos o más gobiernos adoptan, con el apoyo de instituciones comunes, medidas conjuntas para intensificar su interdependencia y obtener así beneficios mutuos". (p. 8)

El enfoque político de la integración regional abarca un carácter vinculante en la toma de decisiones de los miembros del proceso integracionista (Malamud, 2010). Se caracteriza en homogenizar las políticas regionales comunes -que superan el aspecto meramente económico- que dependen de un órgano supranacional a quién se le cede soberanía para que dicte, regule y ejecute a través de la voluntad política de los países expresada en los instrumentos jurídicos regionales y sus órganos gubernamentales resultados que generen bienestar por ejemplo los bienes públicos.

El SICA desde su relanzamiento en el año 2010 empieza a dinamizar su agenda regional para acercarse a una integración positiva retomando la dinámica de políticas públicas como generadoras de bienes públicos regionales, apostando de esta forma a la multidimensionalidad del Sistema, y promoviendo así el desarrollo humano por medio de un proceso de gobernanza regional con "el liderazgo de las instituciones de la integración; la consolidación de una serie de coaliciones entre distintos grupos de interés en el seno de una sociedad civil regional incipiente; y el apoyo de la cooperación internacional". (Santos, 2016: p. 37), ésta última redefine su ingeniería de intervención evolucionando su cooperación desde el ámbito bilateral al regional. 


\section{I. El Derecho Comunitario Centroamericano y los bienes públicos regionales}

De acuerdo a (Miranda, 2013) el Derecho Comunitario es el "conjunto de actos normativos adoptados por los órganos del sistema de la integración regional, que, fundamentados en disposiciones de los tratados internacionales, hacen posible la realización de los objetivos del Protocolo de Tegucigalpa" (pp. II9-120).

El Protocolo de Tegucigalpa de Reforma a la Carta de la Organización de Estados Centroamericanos (ODECA) más adelante referido como Protocolo, en su artículo 35, menciona que éste Tratado originario, sus normas complementarias y derivadas, deberán prevalecer jerárquicamente sobre cualquier "Convenio, Acuerdo o Protocolo suscrito entre los Estados miembros, bilateral o multilateralmente; no obstante, quedan vigentes entre dichos Estados las disposiciones que no se opongan al presente instrumento u obstaculicen el logro de sus propósitos y objetivos".

Al respecto, el Protocolo eleva al ordenamiento jurídico regional de la comunidad Centroamericana bajo el principio internacional lex suprema, que significa que estas normas internacionales de carácter regional estarán sobre cualquier legislación en materia de integración que los Estados suscriban, por lo cual, todos aquellos instrumentos emanados de los órganos de decisión y del sistema institucional tienen una jerarquía prioritaria para garantizar su cumplimiento.

De la misma forma (Salazar, 20I5) expone que el Derecho Comunitario Centroamericano surge a partir de un Tratado Marco constitutivo que regula la materia del Sistema de Integración Centroamericana, se crea un sistema institucional y se ratifican una serie de tratados derivados, que otorgan y afirman las facultades conferidas a las instituciones y a los órganos del sistema de integración. Asimismo, las competencias otorgadas solo pueden tener validez o justificación si persiguen un bienestar común, el bien común que por sí solo un Estado no puede alcanzar, pero sí por una colectividad, cumpliendo con una ficción-jurídica llamada comunidad de Estados.

Este derecho se caracteriza en que las resoluciones emanadas por los órganos y organismos regionales tienen una aplicación uniforme para todos los países, es decir, que existe una homogeneidad, $y$ una aplicación directa e inmediata que entrará en vigencia una vez sean emanadas por sus instituciones y sus órganos de decisión (CCJ, 1997).

Las resoluciones provenientes de las instituciones regionales del Derecho Comunitario pueden ser imperativas o complacientes/voluntarias, en dependencia del sometimiento o ratificación de los Tratados. Se requiere que los poderes ejecutivos de los Estados aprueben estas resoluciones para tener un cumplimiento inmediato de las mismas; por lo tanto, no se requiere aprobación legislativa (CCJ, 1997).

Este marco jurídico de decisiones que poseen los órganos del SICA de acuerdo a su artículo I 2 del Protocolo de Tegucigalpa, se encuentran establecido en el Reglamento para la Adopción de Decisiones del Sistema de la integración Centroamericana aprobado el veinticuatro de junio del año dos mil trece, regula el proceso de creación, adopción, deposito, certificación y publicación de las decisiones emanada por sus órganos.

Este sistema jurídico de la comunidad de Estados centroamericanos posee características propias que abarcan, la obligatoriedad de cumplimiento de las normas y de decisiones políticas derivadas de sus órganos decisorios por los Estados parte, así como la eficacia del funcionamiento de sus órganos y de su producción normativa. En la supremacía jurídica que poseen estas normas se encuentra la validez de las mismas, como el carácter de coerción para garantizar la seguridad jurídica de la comunidad. 
El principio de eficacia directa es otra característica propia de esta institución jurídica, consiste en que las normas comunitarias crean derechos y obligaciones para todos los que se vean involucrados en la aplicación de las mismas, donde se pueden invocar autoridades judiciales y administrativas para su cumplimiento (Mangas y Liñán, 2008).

La Convención de Viena sobre el Derecho de los Tratados de 1969, instrumento jurídico internacional que regula la creación y aplicación de los Tratados Internacionales, establece en su preámbulo que los Tratados son fuentes del Derecho Internacional y del Derecho Comunitario propiciando la creación de espacios de cooperación entre las naciones. Este marco permisible apuesta a acciones donde los Estados puedan innovar sus sistemas políticos, económicos, sociales, culturales y lograr transformaciones significativas en sus países.

Es así que, a través de los Tratados, se forma una estructura normativa que da origen al Derecho de Integración. Instrumentos jurídicos que deben ser observados, aplicados e interpretados de buena fe por los Estados ratificantes para que a partir de su observancia y voluntad puedan cumplir las obligaciones derivadas de los mismos, una vez ratificados y armonizados en la legislación interna por procedimientos constitucionales o legislativos. Este Derecho crea instituciones supranacionales regionales que generan actos normativos vinculantes.

Ante las explicaciones anteriores, se puede inferir que el proceso de integración regional en Centroamérica se constituye como un medio y no un fin para el alcance de bienes públicos regionales, debido a que, la constitución de estos bloques permite una integración sistémica e integral no únicamente economicista, y por medio de estos se puede "generar mejores condiciones para la promoción de acciones cooperativas, que pueden ser consolidadas a través de acuerdos regionales" (Rozemberg y Rozenwurcel, 2012: p. 34).

La integración regional se considera también el vehículo que facilita políticas de desarrollo y contribuye al perfeccionamiento de un marco regulatorio sobre los actores más beneficiados por el mercado regional. Asimismo, promueve una distribución más equitativa de los beneficios de la apertura a este mercado. La integración centroamericana puede ser también el marco de promoción de bienes públicos regionales basados en el desarrollo de las micro y pequeñas empresas en diversos sectores económicos de la región y en la apertura de oportunidades en el mercado regional; o que fomenten la definición de políticas e instrumentos de cohesión social (Caldentey y Romero, 2010).

En este sentido, cuando los Estados nacionales presentan insuficiencias de mecanismos de desarrollo y estrategias para satisfacer las necesidades de sus ciudadanos, las constituciones políticas como norma suprema de éstos, otorgan atribuciones jurídicas para agruparse, asociarse o integrarse con otros Estados, incluyendo la creación de organizaciones con competencias comunes, a fin de obtener respuestas y a su vez, potenciar oportunidades y satisfacer carencias.

Es por ello, que los bienes públicos regionales surgen a partir de una serie de instrumentos jurídicos internacionales, de cooperación, y de decisiones políticas de los Estados que se encuentran próximos geográficamente, con el fin subsanar males comunes o externalidades negativas que afectan ha determinado territorio.

La producción de bienes públicos regionales a través de la integración centroamericana bajo el marco normativo comunitario es un elemento coadyuvante del desarrollo regional. Un eje para lograr estos fines es la promoción de la cooperación internacional y la coordinación y cooperación entre los Estados para la provisión de estos bienes estableciendo áreas específicas de acción 
común. Esta generación de bienes públicos debe producir resultados con impactos positivos capaz de ser cualifícales.

(Caldentey, y Romero, 2010) asevera que la teoría de los bienes públicos vinculado a la integración regional, consiste en establecer áreas prioritarias de cooperación regional en las que se pueda concentrar la acción común para la provisión de estos bienes públicos regionales. Planteamiento que ha ganado en la última década una posición preponderante basada en la promoción del desarrollo de la región, traducida en beneficios tangibles para la sociedad centroamericana.

Devlin y Estevadeordal citado por (Caldentey, y Romero, 2010) señalan algunos elementos determinantes para la creación de bienes públicos regionales. Primero se menciona que los acuerdos comerciales son eficaces promotores para la cooperación; en segundo lugar, es preciso determinar un número limitado de prioridades de cooperación y ampliar la acción a otras cuando las primeras estén consolidadas; en tercer lugar, las instituciones implicadas en la promoción de bienes públicos regionales deben ser fortalecidas técnica, política y jurídicamente y por último, la financiación y evaluación. Etapas indispensables en la cooperación regional que propicia a la seguridad jurídica de la comunidad.

Según (Kaul, et al, 2003) citado en (Velásquez, 2013); la provisión de bienes públicos parte de dos etapas indispensables para su provisión y constitución: I) la toma de decisiones políticas para la creación de estos bienes y 2) la producción de los mismos referido al presupuesto y coordinación. En el marco de la primera etapa, los interesados deciden los bienes a producir, su forma y su distribución; y en la segunda etapa, se implementan estas decisiones, movilizando los recursos necesarios y "ensamblando los bienes públicos mediante una secuencia de acciones estratégicas para que se entreguen sin fricciones". (p. 14)

En la práctica centroamericana la construcción de estos bienes públicos se encuentra centralizada a los órganos de decisión política del Sistema de Integración que son la Reunión de Presidentes y el Consejo de Ministros de los distintos sectores.

La Reunión de Presidentes es el órgano superior del Sistema, constituido por los Presidentes, Jefes de Estado y de Gobierno de los países de la región. Le corresponde definir y dirigir la política integracionista centroamericana, donde se establezcan las líneas de acción de la región, así como las prácticas necesarias que garanticen la efectiva coordinación y armonización de las actividades de los órganos e instituciones, el control, seguimiento y obligatoriedad de sus compromisos adquiridos de los mandatos. Este órgano de decisión le compete el aseguramiento del cumplimiento de las obligaciones contenida en el marco jurídico del SICA, de acuerdo al art. I5 del Protocolo.

El Consejo de Ministros está conformado por los Ministros de los distintos sectores ejecutivos de cada uno de los países miembros, y tienen como atribuciones y competencias darle seguimiento y asegurar la ejecución eficiente de las decisiones adoptadas por la Reunión de Presidentes, tienen atribuciones normativas vinculantes dentro del SICA que se expresan en resoluciones, reglamentos, acuerdos y recomendaciones. Aunado a lo anterior, el Protocolo en su artículo 19 menciona que el Consejo de Ministros poseerá la responsabilidad del tratamiento de los sectores de su competencia así mismo las disposiciones acerca de las atribuciones del Comité Ejecutivo en el artículo 24, literal c) que le corresponde el "establecimiento de políticas sectoriales...".

la Corte es el órgano judicial principal, garantizará el respeto al derecho interno y el derecho comunitario de la comunidad de Estados centroamericanos, cuya jurisdicción y competencia regionales son de carácter obligatorio para los Estados. Posee competencia y jurisdicción propia 
con potestad para juzgar a petición de parte y resolver con autoridad de cosa juzgada, también tiene facultad para emitir ordenanzas de procedimiento y reglamentos generales, operativos o de servicio, y la manera de ejercer sus funciones.

La Corte Centroamericana de Justicia a través de sus resoluciones o sentencias puede consagrar la determinación de un bien de característica de pública. Como indicios incipientes se puede mencionar la demanda del Estado de Nicaragua contra el Estado de Hondura expediente número 5-29-II-99 por incumplimiento de normas comunitarias del Sistema de la Integración Centroamericana (SICA), donde se establece en su considerando 19 de la Sentencia dictada el día 27 de noviembre del año $200 \mathrm{I}$ a la Corte Centroamericana establece la existencia de un "Patrimonio Territorial de Centroamérica".

Esta jerarquía institucional posiciona al Sistema de Integración como una plataforma con facultades de generar bienes públicos regionales, por medio de sus órganos decisorios: la Reunión de Presidentes y el Consejo de Ministros; y faculta a todas las instituciones y sus subsistemas a velar por el cumplimiento de los mandatos emitidos por estos órganos, que deben en primera instancia estar inclinados a los principios de Paz, Libertad, Democracia y Desarrollo.

Dentro del sistema institucional del SICA, se encuentra el principio de subsidiariedad que consiste en el ejercicio de las competencias de los Estados miembros de una comunidad frente al límite entre las decisiones conjuntas de éstos mismos Estados, es decir, el principio que determina el nivel de intervención y de decisiones compartidas, de acuerdo al principio de atribución de competencias que las instituciones reciben para el ejercicio de la acción ya sea nacional o regional.

Según (Sandler, 2013) el principio de subsidiariedad regional tiene por objeto garantizar que los tomadores de decisiones ajusten sus decisiones sobre gastos en bienes públicos de manera tal que reflejen las decisiones de quienes recibirán los beneficios. La subsidiariedad promueve la igualación de los beneficios marginales (sumados todos los beneficiarios regionales) con los costos marginales. Si la jurisdicción decisoria está incluida dentro del área de los efectos positivos indirectos del bien público regional, entonces cabe anticipar una escasez en la provisión del bien, dado que a la hora de decidir su provisión no se contemplaron los beneficios marginales de la totalidad de los beneficiarios.

La subsidiariedad de los órganos dentro del proceso de integración en Centroamérica deberá atravesar una etapa de negoción; de acuerdo al procedimiento realizado por los órganos de poder decisivo del Sistema de integración (la Reunión de Presidentes y el Consejo de Ministros) para la toma de decisiones, ésta actuación debe estar contenido bajo los límites de eficacia y acción comunitaria conforme a los principios y pilares del proceso centroamericano.

De acuerdo a (Salazar y Ulate, 2009), una vez que a los órganos e instituciones del sistema se les ha facultado para realizar propósitos y objetivos comunes, dichos objetivos se pueden obtener de manera más eficaz y eficiente desde el contexto regional que desde una visión nacional, ésa actuación de la comunidad no debe afectar ni sustituir en ningún momento las competencias nacionales en aquellas materias donde no exista una atribución de competencias de los Estados miembros para ser ejercida por los órganos comunitarios.

Si bien la denominación de ciertos bienes públicos no han sido jurídicamente definidos ni concertado en forma expresa por los Estado Miembros por medio de un Tratado, la sentencia relacionada en el párrafo anterior donde se denomina "Patrimonio Territorial de Centroamérica", existe con independencia de que sea reconocido por instrumento jurídico, $y$ a él pertenecen en 
conjunto las superficies de los Estados Miembros que integran la Comunidad Centroamericana o Centroamérica, tal como ellos las estiman.

Ante ésta lógica los bienes públicos además de estar constituidos bajo principios institucionales, deben poseer un enfoque de desarrollo que permita la generación de bienestar e incentivos que promuevan de alguna forma el desarrollo económico sostenible, la cohesión social o la conservación de un bien jurídico protegido.

Es así que la integración regional posee una visión multidimensional del desarrollo, que la coloca como un ecosistema adecuado para la generación de bienes públicos regionales. De todos los esquemas de integración existente en Latinoamérica el proceso centroamericano ha sido capaz de desarrollar en mayor medida este componente, quizá de forma irregular e incompleta todavía (Santos, 2010).

Ferroni y Mody (2004) citado por (Velásquez, 2013) señala que "la oferta de bienes públicos regionales por sí misma, no basta, puesto que, para aprovecharla, los países necesitan contar con una determinada capacidad, conocimiento e infraestructura" (p. 13) es decir, que primero se debe fortalecer la institucionalidad a través del desarrollo de capacidades técnicas-organizativas y en segundo lugar, la creación de departamentos especializados dentro de las instituciones que poseen facultades para construir bienes públicos, esto permitirá la creación de oportunidades para el disfrute social de los bienes.

El diseño jurídico-institucional del Protocolo establece que cada sector goza de plena autonomía para dictar disposiciones de derecho derivado en sus ámbitos de competencia. Los Consejos de Ministros Sectorial e Intersectorial tienen la obligación de tener definidas las materias de su competencia, de tal forma que se sepa cuál es su ámbito de decisión (Salazar, 2015).

Las instituciones comunes dentro del proceso de integración juegan un papel fundamental, ya que son las encargadas de hacer cumplir los acuerdos y compromisos para administrar el buen curso del proceso integracionista, pues también son protagonistas y constituyen los escenarios de la acción colectiva de los actores involucrados y que permiten la descentralización del poder recaído en personas para ser trasladadas a instituciones (Gómez, 2007).

En este sentido, el Sistema de la Integración Centroamericana se considera como un auténtico bien público regional donde su configuración se encuentra sujeto a políticas públicas que permitan incrementar el estado de bienestar de los países comprometidos con el ideal supranacional. La institucionalidad de la integración centroamericana es indispensable como factor clave para la conducción y buena andanza de las políticas públicas creadas a nivel centroamericano, para encaminar los objetivos de bien común regional plasmados en diferentes instrumentos internacionales ratificados por los Estados Centroamericanos (Chorro, 2010).

Ante ésta aseveración podemos considerar que, en Centroamérica, a partir del sistema institucional se consolida una práctica de generación de bienes públicos regionales. En ésta plataforma institucional se han materializado los objetivos y propósitos planteados en las agendas regionales del SICA y en las políticas públicas regionales que promueven estos fines. A continuación se exponen la denominación del nomen iuris ${ }^{12}$ de los bienes públicos en determinadas decisiones desarrolladas por las instituciones del SICA.

Es por ello, que una de las carencias en la región es la distribución de los bienes públicos regionales en el vinculado proceso decisorio, debido a que la oferta de estos bienes, así como su creación se

\footnotetext{
${ }^{12}$ Principio jurídico que significa la relevancia de denominar las cosas por su nombre, "las cosas son lo que son, no lo que las partes pretenden decir que son"
} 
ven limitados a los problemas de cooperación y coordinación entre los países del istmo, debido que para alcanzar los ideales y niveles óptimos de oportunidad y crecimiento para los centroamericanos, es preciso "establecer mecanismos que faciliten la comunicación y brinden confianza a las partes, de modo tal que las incentive a cooperar, acordando una estrategia óptima común” (Rozemberg y Rozenwurcel 2012; p. 4I).

Para poder alcanzar esos niveles de interdependencia en coordinaciones para la construcción de bienes públicos y lograr niveles de integración, es indispensable contar con información precisa y actualizada sobre la problemática social de los países que todavía es un tema pendiente entre los Estados. Lo que se ha constituido como un compromiso reiterado en los diferentes instrumentos jurídicos de la integración social, en las resoluciones y mandatos de sus distintos foros ministeriales.

Sin embargo, a la fecha Centroamérica no cuenta con un sistema de monitoreo del comportamiento de los indicadores sociales, que provea información precisa y actualizada de todos y cada uno de los países del SICA, así como de los diferente programas y actividades regionales para la integración social centroamericana, que permita la toma de decisiones acertadas y facilite conocer los avances y resultados de la actividad desarrollada por la institucionalidad del SICA (CEPAL, 20I2).

Por otro lado, la región presenta formas para aumentar de manera significativa y rápida la oferta de bienes y servicios públicos; sin embargo, los gobiernos enfrentan limitaciones presupuestarias para llevar a cabo sus planes de desarrollo y aumentar la oferta de bienes y servicios. Esto exige una distribución eficiente de los recursos, que conlleva a definir prioridades de alto impacto.

La responsabilidad fiscal debe prevalecer en torno al desempeño del sector público, porque las brechas fiscales y el endeudamiento público no son siempre la vía óptima para mejorar la calidad de vida de los ciudadanos. El impulso de las reformas fiscales es necesario, aun cuando se reconoce que existe resistencia para el incremento de los impuestos y la reducción del gasto corriente.

\subsection{Características de los bienes públicos regionales provistos desde el SICA}

En esta investigación se han planteado las características de los bienes públicos regionales desde un ámbito general a partir de los enfoques económicos, jurídicos y desde la cooperación, sin embargo, existen particularidades de estos bienes desde el contexto centroamericano. En este segmento se pretende identificar elementos que enmarcan la naturaleza de los bienes públicos en el proceso de integración en Centroamérica.

Los bienes públicos generados a partir del Sistema de Integración Centroamericano poseen características sui generis $^{13}$ a la configuración tradicional de los mismos, lo que ha generado la denominación de este status a acciones, productos, incentivos, activos e instrumentos políticos y jurídicos no tradicionales que en ciertas ocasiones pueden confundirse con el garantismo del Estado en la satisfacción de derechos fundamentales.

Por lo antes mencionado, se puede identificar que un bien público en Centroamérica puede tomar forma de una Política Pública, una Estrategia Centroamericana, un Proyecto Regional cuyos beneficios o utilidades puedan gozarse en dos o más países, Instituciones Regionales comunes de

\footnotetext{
${ }^{13}$ Locución latina que significa “que es único en su especie, o es única en su propio género”. En el derecho internacional esta locución adverbial es referida también a aquellos sujetos jurídicos que no cumplen a cabalidad con requisitos esenciales de la hermenéutica jurídica pero que no menoscaba su naturaleza, sino que lo dota de singularidad jurídica.
} 
acción colectiva, Tratados Regionales de Derecho Comunitario, generación de conocimiento por medio de estrategias operativas, espacios de participación política así como todos aquellos instrumentos de derecho derivado o complementario.

Lo importante es que se trata de un campo en expansión que permite legitimar la existencia del Sistema de la Integración Centroamericana y que está en disposición de hacer llegar los beneficios de la integración a la ciudadanía a través de bienes públicos o de garantías de derechos humanos (Santos y Caldentey, sf).

Existen manifestaciones en Centroamérica sobre bienes públicos regionales que pueden tener forma de:

Reglas: a través de Iniciativas de armonización y/u homologación de instrumentos, instrumentos jurídicos regionales, lineamientos y/o estándares regionales, Protocolos y/o guías regionales. Pueden manifestarse como Organizaciones y productos por medio de: instrumentos estratégicos regionales, instrumentos operativos regionales, espacios de diálogo político y/o técnico, mecanismos de coordinación, programas y/o proyectos regionales, estrategias de movilización de recursos, campañas de sensibilización, conocimiento, intercambio de experiencias, modelos y metodologías de intervención, sistemas de monitoreo y evaluación, Iniciativas de fortalecimiento de capacidades, y también pueden manifestarse como Beneficios Concretos: Utilidades directas, Reducción de males comunes (Velásquez, 2013 p. 18).

Las construcciones de bienes públicos regionales manifestados anteriormente deben estar fundamentadas bajo una serie de pilares que permitan evidenciar la gobernabilidad y la institucionalidad del SICA. Como lo menciona (Pérez, Soto y Pellandra, 2013), los bienes públicos deben contener: "I. Acción colectiva 2. Gobernabilidad a cargo de los países 3. Orientación por la demanda 4. Enfoque de abajo hacia arriba 5. Innovación sur-sur 6. Coordinación entre socios estratégicos y 7. Flexibilidad en la solución” (p. 58).

Es decir, éste proceso de construcción de bienes parte primeramente de una suma de esfuerzo de coordinación entre los Estados miembros del SICA, que apuntan a la búsqueda de soluciones comunes que generen utilidades e incentivos donde los Estados puedan beneficiarse. Esta etapa desarrolla un proceso de congruencia de voluntades políticas. De igual forma, los Estados deben elevar sus niveles de cooperación e interacción para satisfacer los propósitos planteados, por ello es preciso definir e identificar esas áreas prioritarias que necesiten intervención ya sea pública o por medio de una colectividad como el proceso de integración.

El enfoque de abajo hacia arriba nos refiere a la dinámica que éstas propuestas de bienes públicos surgen desde un nivel técnico de construcción -donde se valore el alcance, el impacto, incidencia y presupuesto- hacia un nivel de decisión superior para formalizarlo y proveerlo con decisiones políticas vinculantes por parte de la Reunión de Presidentes o el Consejo de Ministros. El elemento de innovación sur-sur que desarrolla Pérez, Soto y Pellandra está referido a que las intervenciones públicas deben realizarse desde los Estados miembros del SICA en un nivel vertical y entre pares.

Por último, es preciso contar con un mapa de actores directos e indirectos para la generación de estos bienes. Los países miembros del SICA en la generación de estos bienes requieren de alianzas estratégicas como la cooperación internacional a través de organismos internacionales para consumar la etapa de financiamiento y asistencia técnica de igual forma los actores sociales como la sociedad civil, la empresa privada y otros actores en el proceso de toma de decisiones para la generación de legitimidad procesal, sin embargo, esta última etapa se encuentra debilitada y requiere de reforzamiento. 
Estos pilares se constituyen como una ruta de construcción de bienes públicos regionales que se generan desde el Sistema de la Integración Centroamericana, por tanto, son características propias de estos bienes en nuestro proceso integracionista.

Existe otra serie de características que rodean a los bienes públicos concebidos en Centroamérica que se vinculan directamente con las características previamente planteadas; en esta investigación se ha logrado identificar las siguientes:

I. La Secretaría General del Sistema de Integración Centroamericana se constituye como un órgano depositario para la provisión de bienes públicos, esto de acuerdo a su carácter comunitario, y como lo establece el artículo 76 de la Convención de Viena sobre el Derecho de los Tratados y el artículo 26 del Protocolo de Tegucigalpa dónde se establece un organismo internacional o el funcionario administrativo de esta organización puede actuar bajo esta calidad cuya función será velar por el cumplimiento de los acuerdos tomados y actuar de forma imparcial en el proceso de ejecución.

2. Protección jurídica regional. Los bienes públicos deben estar protegidos por un régimen especial que permita garantizar la no variación de la titularidad colectiva, la integridad y el flujo de la oferta. Esta protección deviene principalmente de las Constituciones Políticas de los Estados desde un ámbito local y dentro de un sistema comunitario, aunque cabe mencionar que en el ordenamiento jurídico del SICA no existen regulaciones sobre los bienes públicos; sin embargo, existen otros instrumentos de actos normativos vinculantes como reglamentos $y$ resoluciones del Consejo de Ministros en sus distintas especialidades y de la Reunión de Presidentes, todas estas decisiones permiten un marco permisible de protección y de ejecución los bienes únicos que han sido creados desde la estructura centroamericana.

Dentro de esta protección jurídica se contempla la realización de una hoja de ruta técnica que incluya: el alcance, el impacto, la incidencia, los actores directos e indirectos y el diseño presupuestario.

3. Coherentes con los principios de la integración centroamericana (paz, libertad, democracia y desarrollo). La construcción y formulación de bienes públicos deben reflejar en su estructura constitutiva como en sus efectos, los principios y elementos que constituyen el Sistema de la Integración Centroamericana y que sean susceptibles a generar un mayor nivel de paz, libertad, democracia y desarrollo.

4. Capacidad de ser medibles en sus impactos positivos. La evaluación de impactos de los bienes públicos regionales consiste en determinar si una vez ofertados los bienes, cumplieron con su propósito para el cual fueron creados, estas mediciones se realizan a través de un método cualitativo o cuantitativo estadístico, donde se permita evaluar causa y efecto entre la oferta y el bienestar o beneficio generado. Las mediciones de impactos de los productos generados al tema que nos atañe deben cumplir tres variables principales eficacia, eficiencia y equidad.

Abonando al planteamiento anterior se puede establecer que la eficacia de un bien público, una política o un programa expone el grado en que se alcanzan los objetivos propuestos en el momento de su creación. Una iniciativa es eficaz si cumple sus objetivos, teniendo en cuenta la calidad y la oportunidad, sin tomar en cuenta los costos. Un programa o producto es eficiente si cumple sus objetivos, con un uso adecuado, racional u óptimo de recursos. La equidad desde 
el enfoque jurídico del derecho natural se refiere a las leyes y concepto de justicia; a partir del enfoque económico se interpretan los valores, las tradiciones y la ética social y se concreta con la reducción de la desigualdad social en su multi dimensión (CEPAL, 2005).

5. Los bienes públicos generan concordancias de integración más allá de la cooperación entre los Estados. Los bienes públicos generados en el SICA deben estar orientados a crear integración multidimensional con efectos a largo plazo, que tengan un alcance intergeneracional y sus beneficios impacten un alto sector poblacional cuyos resultados sean capaces de impulsar el proceso integracionista. La provisión y oferta de bienes públicos regionales no debe estar orientada a generar sinergias de cooperación por medio de proyectos asistencialistas, cuyos impactos sean momentáneos y estén sectorizados.

6. Presupuesto de ejecución. Los bienes públicos deben poseer un blindaje económico que los proteja a largo plazo y permita su flujo para ser consumido por la población sin características de exclusión y de no rivalidad, los bienes públicos deben además contar con incentivos económicos, políticos o sociales; un mal diseño presupuestario para su oferta puede producir fácilmente externalidades negativas generando males públicos regionales cuando no cumplen los objetivos por el cual fueron creados. Por lo tanto, es clave realizar una identificación de actores directos e indirectos en el diseño técnico de los mismos.

7. Agenda regional. EI SICA ha definido una serie de prioridades para la región desde el año en su relanzamiento 2010. En el año 20II a través del Plan de Acción, se priorizaron las siguientes áreas para la región: Cambio Climático, Gestión Integral del Riesgo, Seguridad Democrática Regional, Integración Social, Integración Económica y Fortalecimiento Institucional, así como todos los instrumentos políticos que se definen en las reuniones de presidentes basados en el marco jurídico de los Tratados Regionales.

Los bienes públicos regionales desde el contexto institucional centroamericano tienen una configuración que permite identificar características propias del proceso integracionista que lo hace distinto a otros esquemas de integración debido a que se encuentra en constante construcción teórica, así como por su pasado integracionista percibido desde el legado de Morazán.

\subsection{Una aproximación del concepto de los bienes públicos regionales desde la SG-SICA}

A pesar de las características planteadas en el acápite anterior, el abordaje teórico y epistemológico de los bienes públicos que se generan desde el SICA aún adolece de una definición formal, que permita ordenar, institucionalizar y darle coherencia integracionista a la oferta y provisión de éstos.

Los instrumentos jurídicos del SICA, así como los actos normativos de la Secretaría General en su facultad reglamentaria, y la Corte Centroamericana de Justicia por medio de Jurisprudencia y opiniones consultivas -en su rol de órgano jurídico principal del Sistema- con atribuciones de construcción del Derecho Comunitario centroamericano no se han pronunciado formalmente sobre la materia. 
El Sistema de la Integración Centroamericana, a partir de su relanzamiento el 20 de Julio del año $2010^{14}$ en la Cumbre de Jefes de Estados y de Gobierno, realizada en El Salvador define 5 líneas de acción estratégicas y prioritarias para la región: seguridad democrática, prevención y mitigación de los desastres naturales y de los efectos del cambio climático, integración social, integración económica y fortalecimiento institucional.

Estas líneas prioritarias permiten el desarrollo de planteamientos para la generación de externalidades positivas frente a externalidades negativas que afectan constantemente a los países del istmo, además se delimita la actuación común y coordinada de los Estados frente a los grandes problemas que aquejan a la región contribuyendo al fortalecimiento de aquellas áreas que emiten beneficios tangibles multidisciplinariamente a los Estados miembros.

En este sentido, es importante señalar la necesidad de contar con una definición propia, ya que permite adecuar, contextualizar y medir los impactos generados de una forma no difusa de los bienes públicos hasta lograr una unificación de criterios. De la misma forma, es importante definir para generar autonomía al Sistema de la Integración Centroamericana por medio del impulso de sus estrategias o planes de desarrollo a través de políticas y acciones que puedan innovar la gobernanza regional para lograr transformaciones significativas en los países del istmo.

Es importante lograr una definición desde un enfoque de numerus apertus, desde una cosmovisión amplia, que no se agota o se limita a una lista cerrada legal ni posea un monopolio absoluto de los Estados para la generación de bienes públicos, que posea una apertura institucional regional de acuerdo al principio de atribución de competencias del derecho comunitario, claramente con restricciones ante atribuciones que solo le corresponden a los Estados. La teoría del numerus apertus logra que las voluntades de los sujetos jurídicos logren la creación de nuevos tipos de derechos reales, a través del principio de la autonomía de la voluntad.

El Sistema de la Integración Centroamericana SICA, ha dado algunos indicios de conceptuales de los bienes públicos, cuyos orígenes principales son las fuentes secundarias o derecho derivado y ha logrado dar un status multidimensional y multidisciplinario en el ámbito regional a los bienes públicos regionales.

Los ejemplos de bienes públicos a continuación descritos no simbolizan los más eficaces generados desde el SICA, sino la categorización material que realizan las instituciones y órganos permanentes del Sistema, para determinar de ciertas acciones desprendidas de las políticas públicas regionales de los sectores ejemplificados.

Aunado a lo anterior, el Consejo de Ministros de la pesca y la acuicultura de los países del Sistema de la Integración Centroamericana ha proporcionado un status jurídico de bien público regional a un proyecto procedimental correspondiente a la elaboración de galletas dulce y saladas a base de productos pesqueros, esto como parte de los resultados de la Política de Integración de Pesca y Acuicultura 2015-2025, este documento resolutorio ha definido como Bien Público Regional a:

Los bienes, servicios o recursos producidos bajo un esfuerzo regional, que posee un valor positivo $y$, por ende, cuantificable y concreto, que está accesible y disponible al mismo tiempo, para uso y beneficio común de todos los habitantes de una zona geográfica o población determinada (p. 2).

\footnotetext{
${ }^{14}$ Es hasta la actual administración del SICA a partir del 30 de junio del 2014, que se empiezan a establecer planteamientos teóricos acerca de los bienes públicos, y su terminología aparece de forma más constante dentro de los resultados de proyectos regionales, así como parte de políticas públicas con alcance regional y productos generados por las instituciones especializadas del Sistema de Integración Centroamericana.
} 
De la misma forma, esta resolución arroja una serie de características propias de este proyecto, para justificar esta designación jurídica de bien público y ha establecido que las galletas dulces y saladas producto del proyecto citado, cumplen con los requerimientos de un bien público regional por cuánto: Es un producto elaborado gracias al esfuerzo de instancias regionales en cuanto a su consumo en condiciones de alta accesibilidad pública; coadyuvan positivamente a satisfacer las necesidades de proteína requeridas por los niños al día; Reúne cualidades nutritivas necesarias para la salud de la población, en especial de la niñez, lo cual se constituye en un complemento nutritivo para incluirlo en los programas de seguridad alimentaria y nutricional; Puede ser distribuida a las diferentes zonas geográficas y en especial a las más vulnerables (p. 2).

En la reunión VII Reunión Extraordinaria del Comité Ejecutivo de SICA/OSPESCA en diciembre 2016, se ha propuesto la realización de un Reglamento de Normativa Pesquera para el uso del Bien Público Regional denominado: "Recetas y procedimientos para la elaboración de galletas dulces y saladas elaboradas con harina de productos pesqueros o acuícolas", propuesta reglamentaria que permite el uso al público de las recetas y procedimientos de este producto por su gran carga energética y nutricional, estos antecedentes permiten confirmar los planteamientos realizados a lo largo de esta investigación de poder darle categoría normativa a los bienes con impactos regionales.

Por otro lado, la Resolución $\mathrm{N}^{\circ} 24$, del Consejo de Ministros de Salud, ha establecido la compra conjunta de medicamentos como un resultado estratégico para la generación de bienes públicos regionales como producto I.3 de la Política de Salud de Centroamérica y República Dominicana, ésta Política establece la necesidad de "conceptualizar, desarrollar y aprovechar la Negociación Conjunta de Precios y Compra de Medicamentos como un Bien Público Regional para su aplicación en otros suministros y tecnologías sanitarias".

Estas resoluciones del Consejo de Ministros de Salud plantean la pertinencia de conceptualizar los bienes públicos para una correcta aplicación y provisión de los mismos, de la misma forma la línea estratégica número I.3.4 de dicha Resolución establece la necesidad de discutir y consensuar posturas comunes en la región, para el impulso de los mismos.

Cabe mencionar que dentro de los principios de la Política de medicamentos de Centroamérica y República Dominicana se encuentra establecido que el reconocimiento al acceso a medicamentos es un derecho humano, además que un medicamento vital o esencial debe ser tratado como un bien público, y que bien común debe prevalecer sobre el bien individual por tanto la política es generadora de bienes públicos y empieza a denominar la pertinencia de estos como derecho humano, todas estas iniciativas políticas se ha logrado gracias a la coordinación del multilateralismo situando en un segundo plano a las negociaciones bilaterales.

No obstante, a la luz de las teorías de los bienes públicos que se han abordado en esta investigación las justificaciones que plantea la resolución no cumple a cabalidad con las características propias e inherentes de los bienes públicos, ya que no se identifica la variable de la existencia tiempo del bien, es un bien que está segmentado, es decir, está focalizado a cierto sector, por lo cual es excluyente y no existe un fácil acceso a su consumo por parte de sus usuarios.

Si bien es cierto, el Sistema de Integración Centroamericana carece en la práctica de denominar sus actos normativos por su nombre, creando de esta forma dispersión en el correcto orden y funcionamiento de sus sistemas de fuentes o naturaleza jurídicas. Este ejercicio es importante para establecer una clara diferenciación entre los distintos actos que ostentan facultativamente los órganos del poder decisorio, esto dificulta precisamente el tratamiento y el efecto que pueden exigir la aplicación de los mismos. 
En este mismo orden de ideas, el SICA aunque carece de esta práctica denominativa posee una vasta lista de bienes públicos que no han recibido este status jurídico ni administrativamente, pero que encierran dentro de su estructura técnica-comunitaria los elementos y características planteados en esta investigación y en la doctrina necesarios para constituirse y convertirse en bienes públicos, ejemplo es el Sistema de Alerta Temprana del CEPREDENAC en el marco de la Política Centroamericana de Gestión Integral del Riesgo, este instrumento encierra dentro de sus líneas de acción la armonización en aspectos social a nivel regional, capacidades de prevención y respuesta fortaleciéndola localmente para superponerla a un ámbito regional, de la misma forma establece herramientas técnico-científicas.

Así mismo, la Estrategia de Seguridad para Centroamérica (ESCA) es un hito de política pública regional con un modo de ejecución coordinado donde participan financieramente la cooperación internacional y los Estados miembros del SICA, esta política ha forjado sinergias de integración y tiene como objetivo la generación de instituciones firmes que permitan el cumplimiento de los principios de la integración regional, así como el mantenimiento del bienestar y la seguridad a través de ejes centrales como el combate al crimen, prevención de la violencia, rehabilitación, reinserción, seguridad penitenciaria y fortalecimiento institucional.

Todos los componentes de la Estrategia de Seguridad, así como los activos, beneficios y acciones políticas que esta Estrategia desarrolla posee un carácter transversal para todas las áreas de la integración centroamericana, ya que es la suma de esfuerzos para lograr una intervención en una problemática estructural, por lo tanto, ésta Estrategia es un bien público en toda su expresión.

Por otro lado, existen otros ejemplos a nivel regional donde se denomina bienes públicos a ciertos recursos inmateriales e intangibles como videos y documentos digitales dentro de una plataforma educativa de la Coordinación de Educación y Cultura del Sistema de la Integración Centroamericana CECC-SICA, institución que cumple con funciones de secretaria técnica en áreas de educación y cultura a nivel centroamericano. Estos recursos denominados como bienes públicos no se generaron de una fuente decisoria de los Ministros de Educación y Cultura ya que no existe evidencia material que lo justifique, sin embargo, cumplen a cabalidad con el rol de generación de conocimiento no excluible y no rival.

Ante este escenario, muchos bienes denominados públicos creados en Centroamérica se encuentran de forma atípica e impura porque no cumplen totalmente con el principio de no rivalidad y con otras características propias planteadas por la teoría económica y jurídica y sobre todo elementos esenciales del Derecho Comunitario Centroamericano.

Aunado a lo anterior, el Sistema de la Integración Centroamericana ha planteado la necesidad de definir su propia configuración de los bienes públicos.

La Dirección de Cooperación Internacional del SICA ha desarrollado una definición no formal ni con vinculación, empero se han esforzado en dar los primeros pasos y expone una conceptualización acerca de los bienes públicos indicada de la siguiente forma: "Un bien, activo o realidad que posee un valor positivo y por ende cuantificable y concreto, que está disponible al mismo tiempo, para uso de todos los habitantes de una zona comprendida por dos o más países” (Sandoval, 2016).

Esta definición introduce al debate de los bienes públicos en Centroamérica clasificaciones materiales más allá de la clasificación clásica de los bienes, sino que también expone que un bien público puede ser un activo, es decir, todo aquello susceptible a ser medible o cuantificable, en esta misma lógica introduce la denominación de la realidad como un bien público, no obstante, esta última clasificación es demasiado intangible, subjetiva y filosófica para la construcción teórica de los bienes públicos debido a que no logra encajar en una ciencia capaz de ser comprobable. 
Por tanto, la construcción de un concepto o una definición de bienes públicos regionales desde el contexto centroamericano debe contener en toda su expresión el espíritu del artículo 4 del Protocolo de Tegucigalpa, por consiguiente, un bien público regional debe ser un activo capaz de:

I. Promover la garantía y respeto de los derechos humanos.

2. Los países ejecutores del bien público regional, así como la región deben mantener un escenario ejecutorio de paz, desarrollo, libertad y democracia.

3. El bien público regional será consecuencia de la interdependencia entre los Estados capaz de generar integración regional más que procedimientos de solidaridad y cooperación.

4. El bien público regional promoverá relaciones entre los Estados basada en marco jurídico y político que promueva la protección regulatoria de los bienes públicos.

5. Los Estados, así como los órganos de decisión del SICA cumplirán de buena fe sus obligaciones, absteniéndose de establecer, convenir o adoptar medidas contrarias al marco jurídico el Sistema de Integración.

6. Un bien público regional deberá contar con la participación de todos los sectores sociales de la comunidad centroamericana, para darle legitimidad a la construcción de los mismos y de esta forma democratizar la participación de la sociedad civil centroamericana.

En este proceso investigativo se trabajó una encuesta que puede ser consultada posteriormente en los anexos, la encuesta se envió vía correo electrónico a 12 expertos vinculados al Sistema de Integración Centroamericano, de lo cual se obtuvieron 4 respuestas, dentro de esta técnica de muestreo teórico con preguntas indagatorias se establecían interrogantes estructuradas tales como: ¿Qué es un bien público regional desde el contexto centroamericano?, en lo que los encuestados establecieron coincidencias en las respuestas de la siguiente manera: "es un bien o servicio, un resultado, un recurso, una infraestructura, una actividad de gestión de conocimiento, soluciones innovadoras de las políticas públicas, investigaciones, estado de arte, documentos prácticos y e instrumentos".

En cuanto a iquién los proporciona?, ésta misma pregunta arrojó lo siguiente: "que son iniciativas de los Estados, los organismos internacionales, y de los órganos centroamericanos".

De acuerdo al efecto que generan, esta misma pregunta estimuló a dar los siguientes aportes: "garantizar la prestación de bienes y servicios a la población, solventar una necesidad conjunta de la sociedad que le construye y que libremente accederá a este, generan un cambio positivo en las condiciones o en las capacidades de la Sociedad Centroamericana y que solo pueden ser abordados desde un ámbito regional".

Ante todos estos planteamientos desarrollados en esta investigación podemos retomar las diferentes doctrinas para construir una definición que permita conjugar la naturaleza del Sistema de la Integración Centroamericana y la epistemología indispensable de los bienes públicos regionales y se puede construir una definición de la siguiente forma:

"Los bienes públicos regionales son aquellos bienes o servicios materiales o inmateriales, generados por la acción colectiva de los Estados, que ofrecen una utilidad capaz de ser medible, que promueva los principios y objetivos de la integración centroamericana, y a su vez, que se encuentre disponible para ser consumido por todos los habitantes de dos o más países".

Este acercamiento de definición permite poder adecuar concepciones a una interpretación universal de los bienes públicos regionales generados desde la integración centroamericana. Poseer una definición propia permite regular e identificar una cartera de bienes públicos, que son necesarios y forman parte de la materialización de los objetivos tangibles de la integración. 
Contar con una postura propia acerca de la identificación de bienes públicos empodera a la comunidad de Estados centroamericanos, a través del sistema institucional intergubernamental al empoderamiento en negociaciones con actores y socios extra regionales, permitiendo identificar los alcances de la función política y administrativa del SICA.

\section{Conclusiones}

El Sistema de la Integración Centroamericana (SICA) no posee una postura propia acerca de la construcción epistemológica de los bienes públicos regionales en Centroamérica, lo que genera dispersión en las denominaciones que los órganos tomadores de decisión e instituciones del Sistema de integración le otorgan a estos bienes, colocando al SICA en una situación vulnerable a la adopción de concepciones extraterritoriales.

Los bienes públicos en Centroamérica tienen características sui generis propias de la identidad centroamericana y de los principios constitutivos del Sistema de Integración.

Es necesario dar conciliación, alcance y contextualización a los bienes públicos hasta lograr una unificación de criterios que permita dar autonomía al Sistema frente a socios externos de la región Centroamericana.

Al no poseer una definición de bienes públicos regionales, se está denominando bienes públicos a todos los productos, resultados, acciones jurídicas y políticas que los órganos e instituciones del SICA generen, como consecuencia se crean una serie de bienes públicos atípicos que no cumplen con las características inherentes del Sistema. Todos estos elementos evidencian que la institucionalidad regional requiere una regulación racionalizada del principio de atribución de competencias a los órganos del Sistema, desprendida del Protocolo de Tegucigalpa.

En cuanto a políticas sociales se encuentran en una deuda social y estructural por lo que la puesta en marcha de la oferta y creación de bienes públicos son escasos por la carencia de una plataforma social establecida en la región, en la que se pueda intervenir con mayor dinamismo.

Las políticas regionales poseen dependencia financiera de la cooperación internacional, se carece de un fondo constante de inversión en política social y la auto sostenibilidad es un punto en la agenda sin resolver. Desde el SICA la creación de bienes públicos no tiene ni puede resolver problemas estructurales profundos, sino que tienen la labor contribuir al desarrollo en todas sus dimensiones y a palear problemáticas comunes o potenciar oportunidades.

A la fecha no existe un procedimiento u hoja de ruta para la construcción administrativa y técnica de los bienes públicos que permita incorporar mecanismos de medición de utilidades.

Existe una influencia marcada en las concepciones teóricas sobre bienes públicos de la cooperación internacional generados desde el Sistema de la Integración Centroamericana.

La Corte Centroamericana de Justicia como órgano jurídico principal del Sistema de la Integración Centroamericana y órgano permanente de consulta no ha recibido consultas vinculantes ni ilustrativas acerca del alcance jurídico de los bienes públicos regionales y sobre su definición dentro del contexto centroamericano. Parte de los aportes que pretende ofrecer esta investigación se ha realizado una consulta ilustrativa con base en los artículos 22 y 23 del Estatuto de la Corte Centroamericana de Justicia y el artículo 72 de la Ordenanza de Procedimientos de este Tribunal.

Las instituciones regionales y los órganos del Sistema de la Integración Centroamericana en el último quinquenio han realizado esfuerzos para darle status de bienes públicos a políticas regionales, 
instrumentos jurídicos y normativos, así como a los productos materiales o inmateriales que resultan de éstos.

EI SICA posee políticas públicas de gran impacto en la región centroamericana que no han sido propuestas para ser denominadas bienes, como ejemplo la Estrategia de Seguridad para Centroamérica y la Estrategia Centroamericana de Desarrollo Territorial que, por su buena práctica tripartita de sociedad civil, Estados y el SICA han logrado niveles de bienestar, integración entre los Estados y poseen en su estructura las características inherentes de los bienes públicos expuestos en esta investigación.

\section{Lista de referencias}

Álvarez, Scarlett. (2012). Una introducción a la cooperación internacional al desarrollo. Honduras. REDUR.

Betancourt, F. (2007). Derecho Romano Clásico. Publicaciones de la Universidad de Sevilla. Sevilla.

Bocalandro, L., y Villa, R. (2009). Bienes Públicos Regionales: Promoviendo soluciones innovadoras en América Latina y el Caribe. Banco Interamericano de Desarrollo. Nueva York.

Caldentey, P y Romero, J. (20I0). La UE y el SICA en una perspectiva comparada La integración regional en una perspectiva comparada La integración regional en una perspectiva comparada. El Salvador. Fundación ETEA/AECID-SICA

Cantarero, D. (s. f). Teoría de Bienes Públicos y Externalidades. Departamento de Economía Universidad de Cantabria. Recuperado de: http://personales.unican.es/cantared/Ep.\%202.2.pdf

Chorro, M. (20I0). La calidad en la producción de bienes públicos regionales frente al cambio histórico. En Cinco ensayos sobre la integración de Centroamérica: Los ganadores del concurso promovido por el $\mathrm{BCIE}$ con motivo de su 50 aniversario. BCIE. Honduras

Comisión Económica Para América Latina y el Caribe (CEPAL). (2005). Evaluación del Impacto. Recuperado de: http://www.cepal.org/publicaciones/xml/7/24337//c12442e.pdf

Comisión Económica Para América Latina y el Caribe (CEPAL). (2009). La integración económica centroamericana y sus Perspectivas frente a la crisis internacional. México.

Dabené, Oliver. (2012). Explaining Latin America's fourth wave of regionalism Regional integration of a third kind. San Francisco. Latin American Studies Association (LASA).

Estevadeordal, A., Frantz, B. Y Nguyen, T.R. (2002), Regional Publics Goods. From theory to practice. Washington, BID y Asian Development Bank. Washington.

Francés, G. (20I2). Provisión de bienes públicos globales y economía política internacional. Anuario de la Facultad de Derecho Universidad Autónoma de México. pp. 39-54. México.

García-Arias, J. (2004). Un nuevo marco de análisis para los bienes públicos: la Teoría de los bienes públicos globales. León, España. Asociación Internacional de Economía Aplicada.

Gómez, L. (2007) Obstacles to Regional Integration in Latin America and the Caribbean: Compliance and Implementation Problem. European Union. Jean Monnet/Robert Schuman Paper Series, Vol. 7.

Hanss-Hernann. (1993). Falacias de la teoría de los bienes públicos y la producción de la seguridad. Kluwer Academic Press. Estados Unidos. 
López, F. (2012). Sistema jurídico de los bienes públicos. Civitas Ediciones.

Malamud, A. (2010). Conceptos, teorías y debates sobre la integración regional. Buenos Aires Recuperado de: http://apps.eui.eu/Personal/Researchers/malamud/ALACIP2010.pdf

Mangas, A,y Liñan, D. (2008). Instituciones y Derecho de la Unión Europea. (pp. 389-449). 5ta edición. Madrid. TECNOS.

Miranda, O. (2013). Derecho de la Comunidad Centroamericana. Cara Parens, Universidad Rafael Landivar. Guatemala.

Morineau, My Iglesias, R. (1998). Derecho Romano. Oxford. México.

Morrissey, O; Willem, D y Hewitt, A (2002). Defining International Public Goods: Conceptual Issues. London. Overseas Development Institute.

Pérez, C.; Soto de la Rosa, H. y Pellandra, A. (20I3). Integración social en Centroamérica: Situación al 2012, tendencias y propuestas. México: CEPAL.

Rozemberg, R., y Rozenwurcel, G. (20I2). Bienes públicos regionales: áreas prioritarias para la cooperación. En los desafios de la integración y los bienes públicos regionales: Cooperación Macroeconómica y Productiva en el MERCOSUR. Serie Red Mercosur 21. Montevideo.

Salazar., C (2015). Protocolo de Tegucigalpa. El Salvador, Editorial ORBI IURE.

Salazar., C y Ulate, E. (2009). Manual de Derecho Comunitario Centroamericano. Talleres de Impresión. San Salvador, p. 107.

Samuelson, P. (1954). The Pure Theory of Public Expenditure. The MIT Press. Recuperado de: http://www.ses.unam.mx/docencia/2007II/Lecturas/Mod3_Samuelson.pdf

Sánchez, Miguel. (1997). Los bienes públicos (Régimen Jurídico). España. Tecnos.

Sandler, T. (2013). Bienes públicos y cooperación regional para el desarrollo: Una nueva mirada. Instituto para la Integración de América Latina y el Caribe (BID-INTAL). No. 36 año 17.

Sandoval, E. (2016). Bienes Públicos Regionales. El Salvador. Secretaria General del SICA.

Santos F, y Caldentey, P. (s.f). Aproximación a las Políticas Públicas de la Integración Centroamericana. Fundación ETEA para el Desarrollo y la Cooperación.

Santos, (20I0). "La integración centroamericana y la participación de la sociedad civil”, preparado para la Universidad de Córdoba, 2010.

Santos, F. (2006). Conceptos fundamentales sobre económica política de la integración regional. España.

Santos, F. (20I4). El debate sobre la renovación del regionalismo y sus implicaciones para Centroamérica. Chicago. Fundación ETEA para el Desarrollo y la Cooperación.

Santos, F. (2016). Los modos de las políticas de la integración. Nicaragua. Revista de Derecho. Vol.20, PP. $31-46$.

Schiff, M., y Winters, L. A. (1997). Regional Integration as Diplomacy, Working Paper on Policy Analysis, World Bank.

SICA. (20I4). La Secretaría General del SICA presenta mecanismo de la cooperación regional. Recuperado de: http://www.sica.int/consulta/Noticia.aspx?idn=92595\&idm=I 
Stiglitz, J.E. (2003): Economía del Sector Público. 3rdEd. Antoni Bosch. Recuperado de: https://finanzaspublicasuca.files.wordpress.com/201 I/I0/economia-del-sector-publico-stiglitz.pdf

Vallejos, M. (2005). Los bienes públicos: Formación de su régimen jurídico. Valencia. Tirant lo Blanch.

Velásquez, A. (2013). La oferta de bienes públicos regionales, en el marco de la integración social centroamericana. En Revista de la Integración Social Centroamericana. Año 3, número 9. El Salvador.

Velásquez, I. A. (marzo de 2009). Los bienes públicos globales y regionales: una herramienta para la gestión de la globalización. Cuadernos unimetanos I, p.I4-19.

\section{Instrumentos Jurídicos}

4to Foro de Alto Nivel. (2005). Declaración de Paris. Publicado en Paris el 2 de Marzo 2005.

CEPREDENAC/SICA. (2010) Política Centroamericana de Gestión Integral del Riesgo. XXXV Reunión Ordinaria de Jefes de Estado y de Gobierno de los países del SICA. 30 de junio de 2010. Panamá

COMISCA/SICA. (20I4). Política Regional de Salud. Resolución de XXXIX. Diciembre de 20I3. Ciudad de Panamá

COMISCA/SICA. (2016). Plan de Salud de Centroamérica y República Dominicana 2016-2020. San Salvador.

Corte Centroamericana de Justicia. (1997). Opinión Consultiva 05-08-97. 5 de Mayo 1997. Managua.

OSPESCA/SICA. (2005). Política de Integración de Pesca y Acuicultura en el Istmo Centroamericano. 25 de Marzo 2015. México

OSPESCA/SICA. (20I6). Propuesta de Resolución declarando bien público regional las galletas saladas y dulces elaboradas con harina de productos pesqueros o acuícolas. VII reunión extraordinaria del comité ejecutivo de SICA/OSPESCA. Managua.

SICA. (I99I). Protocolo de Tegucigalpa. Honduras.

SICA. (20II). Plan de Acción. XXXVII Reunión de lefes de Estado y de Gobierno de los países del Sistema de Integración Centroamericana (SICA). 22 de Julio de 20I I. El Salvador.

SICA. (20I3). Reglamento para la Adopción de Decisiones del SICA. 24 de junio 20I3. Costa Rica.

STM-COMMCA/SICA. (20I3). Política Regional de Igualdad y Equidad de Género del SICA (PRIEG).

Diciembre 2013 